\title{
Genómica del Trypanosoma cruzi. Nuevas oportunidades para tratar el mal de Chagas
}

Jorge A. Huete-Pérez ${ }^{1}$

1. Centro de Biología Molecular de la Universidad Centroamericana (UCA). Apto.69 Managua, Nicaragua. E-mail: huete@ns.uca.edu.ni

Recibido: julio 2006 / Aceptado: octubre 2006

LA SECUENCIACIÓN DEL GENOMA HUMANO PUBLICADA EN FEBRERO de 2001 ha sido considerada como el hito científico más importante del siglo XX. La secuenciación, cuatro años más tarde, de tres parásitos tripanosmatidas, entre ellos el Trypanosoma cruzi, podría ser también catalogada como uno de los acontecimientos científicos más importantes para la salud publica del continente americano. Aquí se presenta un panorama general sobre los resultados más significativos del estudio geonómico del T. cruzi, se abordan los trabajos realizados por nuestro laboratorio en la Universidad Centroamericana, finalizando con una discusión sobre las perspectivas del uso de la genómica en Nicaragua ${ }^{1}$.

Palabras clave: Tripanosomiasis americana-diagnóstico / genoma humanoanálisis.

\section{Introducción}

Con el advenimiento de la era genómica comenzando por el desciframiento del genoma humano (Venter, 2001; Lander 2001), se afianza la noción de que buena parte de las enfermedades podrán tener cura algún día. Se ha pensado en particular de enfermedades, hasta ahora incurables o hereditarias, como el cáncer o el alzheimer. Esta esperanza también se ha extendido a las enfermedades infecciosas como el mal de Chagas, especialmente ahora que, además del genoma humano, se cuenta con la secuencia completa del parásito, T. cruzi (ElSayed, 2005a), así como también las secuencias de otros parásitos similares, Tripanosoma brucei (Berriman, 2005) y Leishmania (Ivens, 2005), causantes de grandes sufrimientos en el mundo.

Desafortunadamente, el enorme impacto que causan las enfermedades parasitarias no ha sido hasta ahora razón de suficiente peso para interesar a los tomadores de decisiones sobre estos temas urgentes de la salud pública. A pesar de toda la tragedia causada en los países en vías de desarrollo, la enfermedad de Chagas, la leishmaniasis y la enfermedad del sueño o tripanosomiasis africana, han sido ignoradas por la gran industria farmacéutica y la investigación moderna, acaso por la poca rentabilidad económica que se esperaría lograr de los tratamientos modernos. Estas enfermedades se conocen como dolencias de pobres, 
porque su transmisión vectorial está ligada a las condiciones de pobreza, malnutrición y viviendas insalubres.

Según la Organización Mundial de la Salud (OMS-OPS), más de 20 millones de personas en América Latina están afectados por el mal de Chagas (World Health Report, 2002), y unas 50.000 personas mueren cada año por esa enfermedad, que es endémica en América del Sur y Centroamérica.

El mal de Chagas o tripanosomiasis americana, se transmite por picadura del chinche, insecto vector también llamado vinchuca y chipo en varios países, que se esconde en grietas y rendijas de casas construidas de madera o adobe y techos de paja. Con la picadura, el $T$. cruzi, parásito causante de la enfermedad, penetra en la herida. Pero la forma de entrada no es el pinchazo, sino na forma más repugnante. Este parásito unicelular se introduce en las células epiteliales por las heces que el insecto defeca mientras extrae sangre de sus víctimas. Una vez en el sistema sanguíneo, el parásito se encamina hacia los órganos vitales. También ocurre la transmisión del parásito por transfusión sanguínea o por vía congénita: de madre a hijo durante la gestación.

Por el torrente sanguíneo, el parásito se dirige a órganos los vitales conllevando a "mega síndromes" que deforman el esófago o el colon y, en ocasiones, puede afectar también al sistema urinario y nervioso. En muchos casos, sin embargo, el parásito radica en los músculos del corazón, en donde puede causar infarto y paro cardiaco.

La persona afectada puede ser portadora durante 15 ó 20 años sin manifestar ningún síntoma. Actualmente no existe tratamiento para los adultos y la única terapia disponible (Nifurtimox y Benznidazole) sólo es eficaz en menores de 15 años y durante la fase aguda, cuando aún no se expresan los trastornos.

En esta revisión bibliográfica, se presenta un panorama general sobre los resultados del proyecto genómico del T. cruzi, cuya secuencia final se publicó en la revista Science del 15 de julio de 2005. Se discute también el trabajo que se efectúa sobre el tema en el laboratorio de la Universidad Centroamericana y se finaliza con una discusión sobre las perspectivas del uso de la genómica en Nicaragua.

\section{Genética y genómica}

El T. cruzi (protozoario flagelado, orden Kitoplastida) tiene un ciclo de vida complejo que alterna cuatro etapas principales en dos hospederos. En el insecto vector se encuentra en forma de epimastigota y trypomastigota cíclico; mientras que en el vertebrado, los estados son tripomastigotas sanguíneo y amastigota intracelular. La transcripción del ARN es policistrónica, el ARNm sufre procesamiento de tipo trans-splicing y los genes no presentan intrones.

Mediante el uso de marcadores polimórficos, se ha demostrado que las cepas de T. cruzi se agrupan en dos grandes bloques taxonómicos: T. cruzi I y II (Brisse S, 2000). Se ha encontrado que el grupo II es más heterogéneo y que puede clasificarse en más detalle en los 
subgrupos II-a hasta II-e. El Te I se ha asociado con la transmisión selvática en marsupiales, mientras que el Tc II con el ciclo domiciliar y en mamíferos.

T. cruzi tiene una estructura clonal (Tibayrenc 1990; Tibayrenc, 2002) siendo que cada linaje se replica asexualmente. La reproducción clonal se evidencia a partir de estudios que muestran la ausencia de genotipos segregacionales y la drástica desviación de HardyWeinberg en regiones geográficas particulares. Otras evidencias incluyen la asociación significativa entre conjuntos separados de caracteres genéticos por RAPD y marcadores de microsatélites. El T. cruzi no condensa cromosomas durante la división mitótica y presenta gran heterogeneidad en el número de cromosomas entre cepas y clones, además de polimorfismo entre cromosomas homólogos.

El genoma total fue secuenciado usando una metodología conocida como de "shotgun" (Whole Genome Shotgun, WGS). La cepa utilizada en la secuenciación fue la Cl-Brener, una cepa de laboratorio que genéticamente es un híbrido resultante de un cruce entre T. cruzi IIb y II-c. Esta selección creó controversia entre los investigadores porque el análisis de una cepa híbrida puede presentar mayores dificultades de entendimiento que un clon puro. Sin embargo, la razón de peso predominante fue que la cepa Brener era la que mejor se había estudiado.

Como resultado de la secuenciación, el genoma se presenta como un listado completo del "código" (secuencia) del parásito, que encierra información relativa a sus características de virulencia, mecanismos de reparación, reproducción, ciclo de vida y metabolismo, entre otras. A partir del descifrado de la secuenciación del ADN genómico presente en el núcleo de los parásitos, utilizando equipos secuenciadores de alta tecnología, se identificaron los genes, se dilucidó su estructura y se determinó su función. Inmediatamente, la principal tarea consistió en el análisis y comparación de los genomas de los tres parásitos utilizando múltiples herramientas bioinformáticas y programas sofisticados para elaborar mapas genéticos.

El genoma final consta de un total de 8740 contigs para un total de $67 \mathrm{Mb}$. De estos, 4087 contigs representan la mayoría de la parte codificante del genoma. El resto representa principalmente regiones repetitivas. Puesto que el parásito es diploide, el análisis se complica por estarse considerando información doble. El genoma diploide se estima en cerca de $110 \mathrm{Mb}$.

La secuenciación del genoma de T. cruzi ha permitido determinar un total de 12000 genes, de los cuales hay un conjunto de 1300 genes nuevos o nunca antes encontrados. Se supone que la acción de estos genes nuevos podría explicar la capacidad del parásito de pasar inadvertido durante años en el organismo y eludir la acción del sistema inmune del paciente. Junto con la descripción del genoma de T. cruzi también se ha presentado una descripción de las proteínas que están presentes cuando el parásito infecta el organismo humano. Se espera que muchas de estas proteínas sean buenas candidatas a vacunas contra el parásito, por lo cual se han abierto nuevas líneas de investigación. En el Cuadro I se recopilan los hallazgos más significativos. 
Cuadro 1. Resultados más sobresalientes del estudio genómico y su ámbito de repercusión y aplicación.

\begin{tabular}{|c|c|}
\hline Datos de la secuenciación del genoma de $t$ cruzi & Ámbito de repercusión \\
\hline $\begin{array}{l}\text { La identificación de secuencias genéticas que intervienen en la } \\
\text { relación hospedero-parásito y en la regulación del metabolismo de } \\
\text { estos microorganismos. }\end{array}$ & fármacos \\
\hline $\begin{array}{l}\text { La identificación de un conjunto de unos } 1300 \text { genes que parecen } \\
\text { tener un rol importante en sus estrategias de supervivencia y } \\
\text { adaptación a los diferentes anfitriones que infecta. }\end{array}$ & Diseño de fármacos \\
\hline $\begin{array}{l}\text { La gran cantidad de secuencias repetidas encontradas, algunas } \\
\text { como genes y otras como regiones inter-génicas. Cerca del } 50 \% \\
\text { del total del genoma corresponde a secuencias repetitivas. }\end{array}$ & Básica/Evolución \\
\hline El genoma diploide contiene un total de 22570 proteínas & $\begin{array}{l}\text { Proteómica } \\
\text { Vacunas/Diagnóstico }\end{array}$ \\
\hline $\begin{array}{l}\text { La gran variedad de proteínas de superficie. Es relevante que un } \\
\text { gran porcentaje del genoma del parásito está dedicado a moléculas } \\
\text { de superficie, las cuales le permiten interactuar con el hospedero. }\end{array}$ & $\begin{array}{l}\text { Inmunidad/Diseño de } \\
\text { fármacos/Vacunas }\end{array}$ \\
\hline
\end{tabular}

Las familias de proteínas que representan los grupos más abundantes son proteínas de superficie: mucinas y proteínas asociadas a mucinas (MASP), el grupo de las Transsialidasas, las Glycoproteínas de superficie Gp63 proteasas, que pueden constituir hasta el 18\% del total. Además, un grupo importante de proteínas abundantes son las Beta-GalactoFuranosil-Transferasas.

Algunas cepas de T. cruzi contienen hasta 130 copias del gen "cruzain" (también conocido como cruzipain o glicoproteína gp57/51) que codifica la cisteíno-proteasa "cruzaína". Otras cepas contienen apenas 5-6 copias, como el caso de la cepa Y. Estos genes están acomodados en repeticiones subsecuentes y, aunque existe polimorfismo, la secuencia es bien conservada. La cruzaína juega un rol crítico en el desarrollo y supervivencia del parásito a nivel intracelular en el hospedero, lo cual ha sido un atractivo para los investigadores que buscan nuevos fármacos (McKerrow, 1999). Incluso se han llegado a identificar algunas regiones importantes de la proteína en los procesos de tráfico intracelular y su relevancia en el procesamiento de la proteasa (, Engel, 2000; Huete-Pérez, 1999).

Genómica comparativa. A partir de la secuenciación del genoma de T. cruzi se sabe que éste es un poco mayor que el de sus parientes cercanos, T brucei y Leishmania, los parásitos que causan la enfermedad del sueño en África y la leishmaniasis. Sin embargo, a pesar de las diferencias, los tres parásitos comparten 6.200 genes y esto ha llamado la atención sobre las posibilidades de encontrar estrategias comunes para una nueva generación de medicamentos que combatan los tres parásitos (El-Sayed, 2005b). Por otra parte, un propósito alternativo sería identificar los genes diferentes que estén relacionados con las patologías específicas de cada enfermedad.

Vacuna contra el mal de Chagas. El uso de las nuevas tecnologías moleculares ha permitido también descartar la vieja teoría que consideraba la cardiomiopatía chagásica 
como una respuesta auto inmune, mientras ahora se le considera más bien como respuesta a la presencia latente del parásito en los distintos órganos. Por lo tanto, una implicación terapéutica inmediata es que todo paciente chagásico, incluyendo el crónico, podría beneficiarse con el tratamiento de rutina para evitar daños al tejido cardíaco. Por lo tanto, habiéndose identificado nuevos genes y posibles proteínas, valdría la pena retomar e intensificar los esfuerzos para la formulación de vacunas contra el mal de Chagas (Garg, 2005).

En ese sentido, los estudios sobre vacunas para leishmaniasis están más avanzados. Ya está prevista la realización de un nuevo ensayo de protección contra L. amazonensis, L. major y L. infantum. En el caso de T. brucei, a diferencia de los otros dos parásitos secuenciados, los científicos consideran que será más complicado desarrollar una vacuna por su capacidad para eludir la acción del sistema inmune. En este aspecto, los estudios genómicos pusieron en evidencia la existencia de un vasto arsenal de genes "dormidos" que permiten al parásito escapar a la respuesta inmune del hospedador.

Genoma del chinche. Los chinches (hematófagos del orden Hemíptera), son los vectores de transmisión del mal de Chagas. Recientemente se han empezado estudios para decodificar su genoma, lo cual puede dar la clave para que la ciencia devela totalmente cómo se origina y transmite el mal de Chagas y combatir este terrible mal. La decodificación de este genoma aportará conocimientos en la búsqueda de soluciones.

Este mapa genético lo realizarán científicos de varios países como Argentina, Brasil, Uruguay, Paraguay y Chile, con el apoyo del Instituto Pasteur de Francia y de la fundación Argentina "Conicet”. Esta iniciativa regional también empleará el método de secuenciación llamado "shotgun". Se fraccionará el genoma de los insectos a estudiar y se secuenciarán los extremos de esos fragmentos. Finalmente, se ensamblarán todas las lecturas hasta rearmar el conjunto de sus genes. Según los planes, se trabajará con ejemplares de tres de las especies triatominas que transmiten el parásito del Chagas: Triatoma infestans, Triatoma dimidiata y Rhodnius prolixus, todas las cuales existen en Centroamérica.

Todos estos insectos triatominos se establecieron primeramente en medios silvestres, pero con el tiempo se fueron adaptando a residir dentro de las viviendas humildes de paredes de adobe y techos de paja y también peri-domiciliarmente, en gallineros y establos. De esta forma, los insectos se convirtieron en la principal vía de transmisión del Chagas. Algunos tipos de triatominos son principalmente domésticos o bien silvestres, pero pueden alternarse cuando se perturba su hábitat natural. Estas observaciones deben tomarse en consideración en las estrategias de eliminación del vector y reducción de la transmisión vectorial.

\section{Investigaciones en la UCA}

El mal de Chagas constituye una de las mayores causas de morbi-mortalidad entre los habitantes de las regiones pobres de América Latina. En Nicaragua no se tiene datos definitivos sobre la magnitud real del problema, los datos preliminares indican una situación preocupante. En lo que respecta a Nicaragua, a pesar del enorme esfuerzo de profesionales y técnicos, el país no cuenta con estudios científicos suficientes que permitan 
una valoración confiable de la magnitud real de la situación epidemiológica. Sin embargo, una encuesta de 2000 realizada por el Ministerio de Salud (MINSA), entre escolares de 7 a 14 años, refleja la gravedad del asunto: la mitad de los Municipios endémicos se consideran de "alta transmisión activa", mientras la sero-positividad anda cerca del 10-20 por ciento en muchos de esos Municipios. En otros lugares esta cifra podría pasar del 40 por ciento.

El Chagas presenta un curso clínico variable que oscila desde casos asintomáticos a casos crónicos. La variabilidad genética de T. cruzi puede es determinante para el tropismo diferencial a tejidos y, consecuentemente, para las formas clínicas de la enfermedad.

Las más recientes investigaciones conllevan a proponer una consideración importante: las distintas cepas del parásito muestran diferencias en la virulencia, distinción que puede deberse a características genéticas propias de cada cepa. Las observaciones experimentales muestran que hay personas infectadas con el parásito, pero que nunca desarrollan la patología; mientras en otras, la enfermedad es fulminante. Para abordar correctamente el problema del mal de Chagas, se requiere conjugar dos factores que intervienen en la manifestación de la enfermedad: paciente y parásito. La información disponible, tanto acerca del hospedero humano como del parásito causante de la enfermedad, deberá ser estudiada no aisladamente sino en conjunto.

Gracias a una colaboración entre la Universidad de California, UCSF, y el Centro de Biología Molecular de la Universidad Centroamericana, UCA, se valoran aspectos moleculares del parásito concernientes a su variabilidad genética. Puesto que las cepas del parásito se propagan de manera clonal, dando lugar a numerosas variantes, un objetivo de esta investigación es conocer la variación de la información genética contenida en cada cepa del parásito para definir sus implicaciones a nivel epidemiológico. Un ejercicio inicial del grupo de trabajo dio lugar a una revisión bibliográfica (Huete-Pérez, 2005) publicada en colaboración con la Universidad de California y el Instituto de Investigaciones Genómicas de Estados Unidos (TIGR), grupo participante de la secuenciación genómica de los tres parásitos tripanosomatidas.

ElCentro de Biología Molecular se ha propuesto desarrollar una línea de investigación pionera en el país, para estudiar la eco-epidemiología, la biología y la genética de tripanosomas, así como de los vectores de transmisión. En el Cuadro 2 se presentan detalles de los objetivos de estos estudios correlacionados con su metodología y área del conocimiento. 
Cuadro 2. Líneas de investigación relativas a la descripción molecular y aspectos relativos al mal de Chagas

\begin{tabular}{|l|l|}
\hline Líneas de investigación en la UCA & $\begin{array}{l}\text { Área del } \\
\text { conocimiento }\end{array}$ \\
\hline $\begin{array}{l}\text { Determinar la distribución y prevalencia de T. cruzi, sus vectores y } \\
\text { reservorios en Nicaragua; especialmente en regiones de alta densidad. }\end{array}$ & $\begin{array}{l}\text { Genética de } \\
\text { Poblaciones } \\
\text { Biología } \\
\text { Molecular }\end{array}$ \\
\hline $\begin{array}{l}\text { Estudiar la incidencia y prevalencia de la enfermedad de Chagas, en } \\
\text { las poblaciones rurales donde se detecte más el parásito y en los } \\
\text { bancos de sangre que reciben donantes provenientes de zonas } \\
\text { endémicas (Carazo, Masaya). }\end{array}$ & $\begin{array}{l}\text { Biología } \\
\text { Molecular }\end{array}$ \\
\hline $\begin{array}{l}\text { Determinar la estructura genética y dinámica poblacional de las } \\
\text { especies de Triatominae a nivel de país. }\end{array}$ & $\begin{array}{l}\text { Genética de } \\
\text { Poblaciones }\end{array}$ \\
\hline $\begin{array}{l}\text { Identificar la estructura genética y dinámica poblacional de las } \\
\text { poblaciones nicaragüenses de T. cruzi. }\end{array}$ & $\begin{array}{l}\text { Genética de } \\
\text { Poblaciones }\end{array}$ \\
\hline $\begin{array}{l}\text { Establecer las interacciones parásito-mamífero y describir el tropismo } \\
\text { de tejidos de las poblaciones nicaragüenses de T. cruzi. }\end{array}$ & $\begin{array}{l}\text { Inmunología } \\
\text { Clínica }\end{array}$ \\
\hline $\begin{array}{l}\text { Establecer nuevas formas de diagnóstico molecular para uso de la la } \\
\text { comunidad médica y del Ministerio de Salud. }\end{array}$ & $\begin{array}{l}\text { Diagnóstico } \\
\text { Molecular }\end{array}$ \\
\hline $\begin{array}{l}\text { Identificar aspectos inmunológicos del mal de Chagas y marcadores } \\
\text { moleculares de poblaciones humanas de zonas endémicas del mal de } \\
\text { Chagas. }\end{array}$ & $\begin{array}{l}\text { Inmunología } \\
\text { Clínica/Biología } \\
\text { Molecular }\end{array}$ \\
\hline
\end{tabular}

\section{Perspectivas}

Al igual que ha ocurrido con los demás organismos secuenciados, incluyendo a los seres humanos, la descripción total del genoma de T. cruzi es apenas el inicio, que marca la pauta para seguir buscando nuevas rutas metabólicas y moléculas nuevas que parecen ser muy importantes para el parásito. La secuencia será una gran herramienta y guía del contenido genético por la cual se podrá saber qué moléculas usan estos patógenos para establecer la infección en humanos, y qué moléculas se pueden empezar a utilizar para formular nuevas quimioterapias y preparar vacunas. La descripción del genoma de los parásitos que provocan estos trastornos abre una nueva etapa en la investigación de estas patologías, particularmente a nivel de diagnóstico y la clínica. En particular, se piensa que las nuevas investigaciones post-genómicas habrán de destinarse a la búsqueda de nuevas moléculas que sirvan de diana de nuevas terapias y vacunas. El hecho de confirmarse la abundancia de genes de cruzain en el genoma de T. cruzi reafirma la importancia de su proteína en todo el ciclo celular y la infección del parásito. Sin embargo, se prevé que en los próximos años se definan nuevas moléculas como diana de más investigaciones en el diseño de fármacos.

En la secuenciación del genoma de T. cruzi participó un equipo de investigación formado por científicos latinoamericanos (de Argentina, Brasil, y Venezuela) y de otros países industrializados. Aunque lo que motivó este ambicioso proyecto fue la necesidad de 
encontrar nuevas formas de combatir el mal de Chagas, con la información obtenida se podría, además, descubrir nuevos mecanismos biológicos hasta ahora insospechados, que eventualmente podrían tener alguna aplicación más allá del tratamiento del mal de Chagas. De este modo, queda demostrada la validez de estas redes que crean sinergias de impacto indiscutible en el entendimiento de estos problemas de salud pública y que, además, crean un gran valor adicional para el desarrollo científico de la región.

Dado que resulta muy costoso el equipamiento de un laboratorio de biología molecular y de genómica, se presentan enormes dificultades para echar a andar la ciencia genómica en países como Nicaragua. Acaso la manera mas adecuada sea la de crear redes nacionales que permitan cooperar científicamente y compartir recursos. Además, el trabajo de proyectos conjuntos con laboratorios genómicos de alto nivel de América Latina como Chile, México y Brasil, permitirían un abordaje mas completo de las problemáticas existentes. La existencia de un buen número de jóvenes expertos en programas informáticos podría significar una buena oportunidad para incursionar y promover el desarrollo de la bioinformática en el país. Esto, sumado al auge creciente de la biotecnología en Nicaragua, debería repercutir en un progreso considerable de las ciencias biomoleculares y genómica.

Por otra parte, las cifras alarmantes que maneja el Ministerio de Salud deberían obligar al Estado y la sociedad a tomar medidas drásticas y apremiantes, y movilizar fondos que estimulen y promuevan la definición del problema en el ámbito del tratamiento de la niñez enferma y la sanidad pública.

\section{NOTAS}

1 Artículo basado parcialmente en la intervención del autor en el Tercer Congreso Nicaragüense de Biotecnología, el 20 de abril de 2006

\section{Referencias bibliográficas}

-BERRIMAN M. et al., (2005). "The genome of the African trypanosome Trypanosoma brucei". Science. 2005 Jul 15;309(5733):416-22.

-BRISSE S. et al., (2000). "Identification of six Trypanosoma cruzi phylogenetic lineages by random amplified polymorphic DNA and multilocus enzyme electrophoresis". Int J Parasitol. Jan;30(1):3544.

-EL-SAYED, N. M. et al., (2005a). “Comparative genomics of trypanosomatid parasitic protozoo”. Science, Jul 15;309(5733):404-9.

-EL-SAYED, N. M. et al., (2005b). "The genome sequence of Trypanosoma cruzi, etiologic agent of Chagas disease". Science. 2005 Jul 15;309(5733):409-15.

-ENGEL, J. C. et al., (2000). "Upregulation of the secretory pathway in cysteine protease inhibitorresistant Trypanosoma cruzi”. J Cell Sci. 2000 Apr;113 ( Pt 8):1345-54.

-GARG, N. y BHATIA, V., (2005). "Current status and future prospects for a vaccine against American trypanosomiasis” Expert Rev Vaccines, Dec;4(6):867-80.

-HUETE-PEREZ, J. A. et al., (1999). "Protease trafficking in two primitive eukaryotes is mediated by a prodomain protein motif”. J Biol Chem. Jun 4;274(23):16249-56. 
-HUETE-PEREZ, J. A. et al., (2005). "Genomic and proteomic approaches for Chagas' disease: critical analysis of diagnostic methods". Expert Rev Mol Diagn, Jul;5(4):521-30.

-IVENS, A. C. et al., (2005). "The genome of the kinetoplastid parasite, Leishmania major". Science. Jul 15;309(5733):436-42.

-LANDER, E. S. et al., (2001). Initial sequencing and analysis of the human genome". Nature, Feb 15;409(6822):860-921.

-MCKERROW, J. H. (1999). "Development of cysteine protease inhibitors as chemotherapy for parasitic diseases: insights on safety, target validation, and mechanism of action". Int J Parasitol. Jun;29(6):833-7.

-TIBAYRENC, M. y AYALA, F. J., (2002). "The clonal theory of parasitic protozoa: 12 years" on, Trends Parasitol, Sep;18(9):405-10.

-TIBAYRENC, M. et al., (1900). "A clonal theory of parasitic protozoa: the population structures of Entamoeba, Giardia, Leishmania, Naegleria, Plasmodium, Trichomonas, and Trypanosoma and their medical and taxonomical consequences". Proc Natl Acad Sci U S A. Apr;87(7):2414-8.

-VENTER, J. C. et al. (2001). “The sequence of the human genome”. Science, Feb 16;291(5507):130451.

-WHO, The World Health Report (2002). (World Health Organization, Geneva, 2002). 